\title{
Prospective and retrospective timing by pigeons
}

\author{
J. Gregor FetTERMan \\ Indiana University-Purdue University, Indianapolis, Indiana \\ AND \\ P. RiCHARD KILLEEN \\ Arizona State University, Tempe, Arizona
}

\begin{abstract}
Pigeons discriminated between two pairs of durations: a short set $(2.5$ and $5 \mathrm{sec})$ and a long set $(5$ and $10 \mathrm{sec})$. The pairs were intermixed within sessions and identified by the colors on the signal and choice keys. Once the task was learned, the pigeons experienced the following three conditions seriatim: (1) The signal key was made ambiguous about the test change, but the choice keys were informative (retrospective); (2) the signal key identified the test range, but the choice keys did not (prospective); (3) probe trials were introduced in which the color of the center key signaled one test range, but the color of the choice keys signaled the other test range (inconsistent). Accuracy of choice decreased in the retrospective condition and, returned to baseline levels, was higher under the prospective condition than under the retrospective condition. In a final condition, referred to as conflict trials, the center-key color signified one test range and the choice-key colors the other range. The results from these conflict-inconsistent tests indicate that choice behavior was largely controlled by the signal-key color and not by the choice-key color. We relate these findings to different approaches to timing in animals.
\end{abstract}

Time is a dynamic and extended (protensive; Marks, 1991) dimension of stimuli (Fetterman, 1996) that has been an intensive focus of theory and research for the last 30 years (e.g., Church, 1984; Church \& Deluty, 1977; Gibbon, 1977; Grondin, 2001; Killeen \& Fetterman, 1988; Stubbs, 1968). Time as a dimension of stimuli differs in fundamental and interesting ways from intensive dimensions such as brightness (Guttman \& Kalish, 1956) or loudness (Jenkins \& Harrison, 1960), which occupied early research on stimulus control (Terrace, 1966). There is no obvious exteroceptive stimulus or mediating receptor for the temporal dimension: "Events are perceivable, but time is not" (Gibson, 1975). Time is a dynamic stimulus, along which one temporal value cannot be discriminated from another until the carrier signal (e.g., a light or a tone) terminates, or at least passes some threshold value.

Simple procedures such as periodic presentations of response-contingent food do not require a subject to discriminate between different values of a temporal stimulus, but if the animal is hungry, it inevitably does so; Killeen and Fetterman (1988) referred to this sense of location in the temporal stream as immediate timing. In more complex procedures, two or more durations in which the subject does not know in advance which duration will be presented are used. Consider a standard temporal discrimination in which a pigeon or rat is taught to discriminate a 2-sec signal from a 4-sec signal by making one response after the shorter value and a different one after the longer value. At the onset of the signal, the pigeon (or rat) cannot determine whether the shorter or longer signal will be presented, and the probability that the stimulus is long changes during the signal (the dynamic property of temporal discriminations). The subject can determine the duration of the signal only after the signal has lasted well past the shorter interval. There must be a suspension of judgment until one interval of time can be properly discriminated from another interval of time. This dynamic property of temporal events and its implications for timing behavior are the major foci of this article.

Under standard temporal discrimination tasks, a subject learns to make choices appropriate to the values of two stimuli. In the dual-timing task used in this experiment, pigeons learned two temporal discriminations involving different pairs of intervals ( $2.5 \mathrm{vs} .5 \mathrm{sec}$ and $5 \mathrm{vs} .10 \mathrm{sec})$ intermixed within sessions. Under the dual-timing task, pigeons were cued about the test range by the color of a center-key light stimulus and choice-key light stimuli, all of which were identical for a particular test range (red for the short range and green for the long range). This dualtiming task is similar to a procedure used by Machado and Keen (1999), who also intermixed two test ranges within sessions using a temporal discrimination task. Their test ranges were 1 versus $4 \mathrm{sec}$ and 4 versus $16 \mathrm{sec}$, with the test range cued by different choice-key colors.

In other conditions of our experiment, the cues before or after the temporal stimuli were ambiguous with regard to the test range. In one condition (retrospective), the color of the center-key light was ambiguous with regard to test

J. G. Fetterman, gfetter@iupui.edu 
range, but the choice-key stimuli identified the test range after the center-key stimulus was turned off. In another condition (prospective), the center-key light signified the test range, but the color of the choice keys was ambiguous with regard to the test range. The question was whether cuing only during or only after the temporal stimulus affected temporal discrimination relative to a condition in which the subjects were cued both during and after the stimulus. Does the ability to anticipate the test range facilitate discrimination relative to a condition in which anticipation was not possible? Is the decision made during the sample, so that the range information introduced at the choice stage adds little to accuracy?

The prospective/retrospective distinction also appears in the delayed matching to sample (DMTS) literature. In DMTS, a subject views a sample (e.g., red), the sample is taken away for some period of time (retention interval), and the choice/comparison stimuli are presented after the retention interval. A response to the comparison stimulus that is the same as the sample is reinforced, whereas the alternate response is not reinforced. The question is whether the subject is remembering retrospectively (i.e., looking back when tested at the end of the trial) or prospectively (i.e., looking forward during the period that precedes the comparison stimuli). There is evidence that samples may sometimes be coded retrospectively (Urcuioli \& Zentall, 1986), that at other times they may be coded prospectively (e.g., Roitblat, 1980; Urcuioli \& Zentall, 1992), and that in some instances both tactics may be used (Honig \& Thompson, 1982).

After the baseline, prospective, and retrospective conditions were completed, a series of probe tests were carried out. The probes were intermixed with baseline training conditions in which both center- and choice-key colors cued the test range. During the probe trials, a conflict between the color of the center-key and choice-key lights was introduced. For example, a trial might begin with a red light on the center key, signifying the short test range, but end with green lights on the choice keys, signifying the long range. The probe trials of greatest interest were those in which the center-key duration was common to both the short and long test ranges $-5 \mathrm{sec}$, a duration indicating that a long choice in the shorter test range (2.5 vs. $5 \mathrm{sec})$ was appropriate but calling for a short response in the longer test range ( 5 vs. $10 \mathrm{sec}$ ).

The probe tests were similar, but not identical, to probe tests used by Machado and Keen (1999). In their procedure, the choice-key colors cuing the test range were a houselight and a white center-key light. By contrast, in our procedure the center-key light cued one range, and both choice-key lights cued the opposite range.

Our probe tests bear on a long-standing distinction on the nature of temporal coding, whether that code is analogical (e.g., a pulse number value in pacemaker counter models of timing; Church, 1984) or categorical (reflecting a label for the temporal stimuli, short vs. long; Kraemer, Mazmanian, \& Roberts, 1985). If the birds compare the pulses in working memory with a retrieved pulse number for short and another for long, given the choice-key colors, and then decide which sample is closest to that value (Wearden, 2003), they should choose according to the test range cued by choice-key colors: The red choice keys inform the pigeon to respond long, and the green choice keys inform the pigeon to respond short. If, on the other hand, a pigeon labels the center stimulus as short or long while experiencing it, choices should be appropriate to that label: long after red center-key periods and short after green center-key periods.

\section{METHOD}

\section{Subjects}

Four adult male Silver King pigeons (Columba livia) maintained at $80 \%$ of their free-feeding weights served as subjects. The pigeons had free access to water and grit and were housed individually in a room with a 12:12-h day:night cycle with dawn at 7 a.m. The pigeons had served previously in an experiment similar to the one described here.

\section{Apparatus}

The experimental enclosure was a standard BRS-LVE three-key operant chamber $(32 \mathrm{~cm}$ high $\times 34 \mathrm{~cm}$ wide $\times 34 \mathrm{~cm}$ deep). The pecking keys were accessible through $2-\mathrm{cm}$ circular openings in the work panel on the front wall, with the centers of the openings $6.3 \mathrm{~cm}$ apart, $25 \mathrm{~cm}$ above the chamber floor. A force of approximately $0.15 \mathrm{~N}$ was required to operate each of the keys. The feeder opening was located directly below the center response key and measured $5 \mathrm{~cm}$ on all dimensions; the bottom of the feeder opening was $10 \mathrm{~cm}$ above the chamber floor. When activated, the food hopper provided $3 \mathrm{sec}$ of access to mixed grain. White noise served to mask extraneous sounds; additional masking and ventilation were provided by an exhaust fan attached to the chamber wall. Experimental events were scheduled and recorded by an IBM PC.

\section{Procedure}

Baseline condition. All of the pigeons were trained on a temporal discrimination task with the following characteristics: Trials began with the illumination of the center key with red or green light; each color occurred equally often. The presentation of the colors was randomized within blocks of 10 trials, with the constraint that each block contained equal numbers of each color. The key light remained on for some duration and went off independently of behavior; the offset of the center-key light was accompanied by the onset of lights behind the left and right keys. The colors of the side-key lights were the same as that of the center-key light (see Figure 1). A peck to one

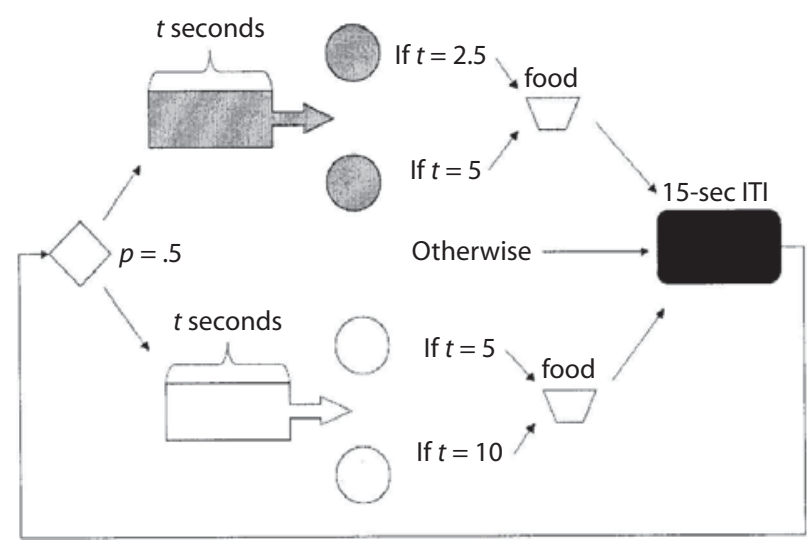

Figure 1. The design of the baseline condition. 
side key was correct after short durations of the center-key light (the sample), and a peck to the other side key was correct after long durations of the sample. The key location that was correct for short and long responses was counterbalanced across birds. A noncorrection procedure was used. Correct responses resulted in 3-sec access to mixed grain, followed by a 15 -sec intertrial interval (ITI), during which all lights were off. Incorrect responses produced the ITI directly. Sessions ended after 100 trials.

Two sets of temporal stimuli were intermixed within sessions: a short set $(2.5$ and $5 \mathrm{sec})$ and a long set $(5$ and $10 \mathrm{sec})$. Red key lights (center and side keys) signified the short set, and green key lights signified the long set. In both cases, a subject's task was to peck one choice key after the shorter duration of a set and the alternative choice key after the longer duration of that set. The choicekey-duration assignments were categorically consistent across test ranges such that, for instance, if the left key was correct after $2.5 \mathrm{sec}$ of red (the short value), it was also correct after $5 \mathrm{sec}$ of green (the short value). The pigeons received equal numbers of trials with each set of temporal stimuli and equal numbers of trials with each duration in a set. All of them received 25 sessions of baseline training, and the last 5 sessions were used for data analysis.

Prospective and retrospective conditions. After baseline training, all of the pigeons were exposed to conditions in which the values of the set of temporal stimuli were ambiguous during one segment of the trial but not during the other. In the prospective condition, the center-key color (red or green) signified the values of the test set, but the color of the choice-key lights (amber) was the same for both test ranges, providing no information about test range. If the center-key color was red, the light was on for 2.5 or $5 \mathrm{sec}$. If the center-key color was green, the light was on for 5 or $10 \mathrm{sec}$. The correct (reinforced) response depended on the duration of the center-key light and the test range cued by the color of the center-key light.

In the retrospective condition, all trials, irrespective of the test range, began with the onset of an amber light behind the center key; the amber key light remained on for $2.5,5$, or $10 \mathrm{sec}$. Following the offset of the center-key light, the side keys were illuminated with red lights when the trial involved the short test range and illuminated with green lights when the trial involved the long test range. The reinforcement contingencies for correct choices were based on the test range cued by the choice-key colors. For example, if the center-key light lasted $5 \mathrm{sec}$ and the choice-key lights were green, a response to the short key was correct, but if the choice-key lights were red following a 5-sec center-key period, a response to the long key was correct. Correct responses resulted in 3-sec access to mixed grain, and incorrect responses initiated the ITI. Figure 2 outlines the paradigm. Each pigeon was exposed to the prospective and retrospective training conditions for 25 sessions, and the last 5 sessions were used for data analysis. The order of exposure to conditions was counterbalanced.

Inconsistent trials. After exposure to the prospective and retrospective conditions, all of the pigeons were returned to the baseline training regimen, under which both center- and side-key colors signaled the test range. After 25 sessions of reexposure to baseline conditions, the birds received probe trials that introduced a conflict between the cues provided by the center and side keys. Under one set of probe trials, red center-key periods, signaling the short test range, were followed by green choice-key periods, signaling the long test range. In another set of probe trials, green center-key periods, signaling the long test range, were followed by red choice-key periods, signaling the short test range. There were 10 probe trials of each kind; choice responses on these trials were not reinforced. Sessions containing probe trials were separated by 2 sessions of baseline training. The data of primary interest were from the probe trials that involved center-key durations (red or green) lasting $5 \mathrm{sec}$ (the longest interval for the short range and the shortest interval for the long range). These trials provided a different method of assessing whether center-key stimuli or comparison exerted more control over choice.

The probe tests that we used were similar, but not identical, to probe tests given by Machado and Keen (1999). In their procedure,
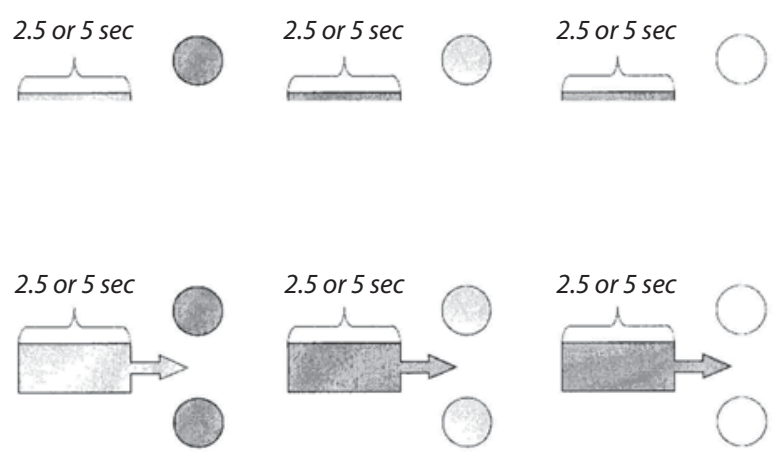

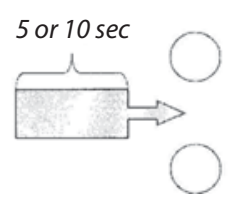

Retrospective

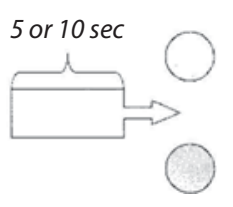

Prospective

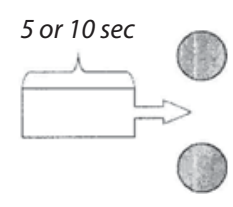

Inconsistent
Figure 2. The stimulus arrangements during the remaining conditions of the experiment.

the center-key color cuing the test range was followed by choicekey lights, one of which was appropriate to the center-key color, the other signifying the alternate test range. By contrast, in our procedure, the center-key light cued one range and both choice-key lights cued the opposite range.

In all statistical tests, we used an alpha of .05 as the rejection criterion.

\section{RESULTS}

Figure 3 shows the results of conditions in which the identity of the test range was cued during both the sample and the choice phases (unfilled bars) and when the test range was ambiguous until the choice keys were illuminated (filled bars). The top panel shows these comparisons for the short set $(2.5 \mathrm{vs} .5 \mathrm{sec})$, and the bottom panel shows data for the long set $(5 \mathrm{vs} .10 \mathrm{sec})$. Data are shown for each pigeon, with the means of those data on the far right of each panel.

When information about test range was available during and after the sample, accuracy was higher than when that information was available only at the end of the trial. The difference in the two conditions represented in the figure appears to be greater in the top panel (short range) than in the bottom panel (long range). The median difference in accuracy (percent correct) between the two conditions for the short range was $22 \%$, and the median difference in accuracy for the long range was $9 \%$; the direction of the difference is the same for all birds across both ranges. Interestingly, Pigeon 52 needed the range information during the short set sample; without it, his behavior fell to chance in the short set but not in the long set.

A two-way ANOVA was used to evaluate the reliability of the trends in Figure 3. The factors were cue type and test range. The main effect of cue type was significant $[F(1,3)=30.35]$. The main effect of test range was not significant $(F<1)$. The interaction between the factors 


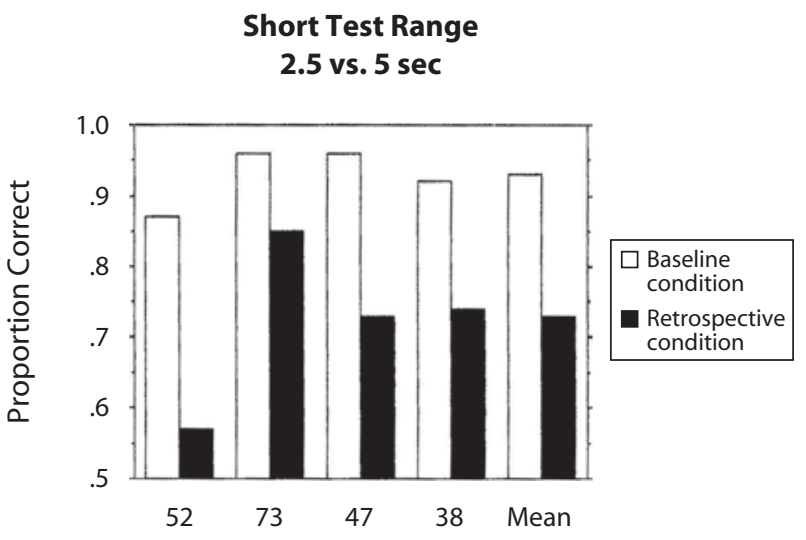

Long Test Range

5 vs. $10 \mathrm{sec}$

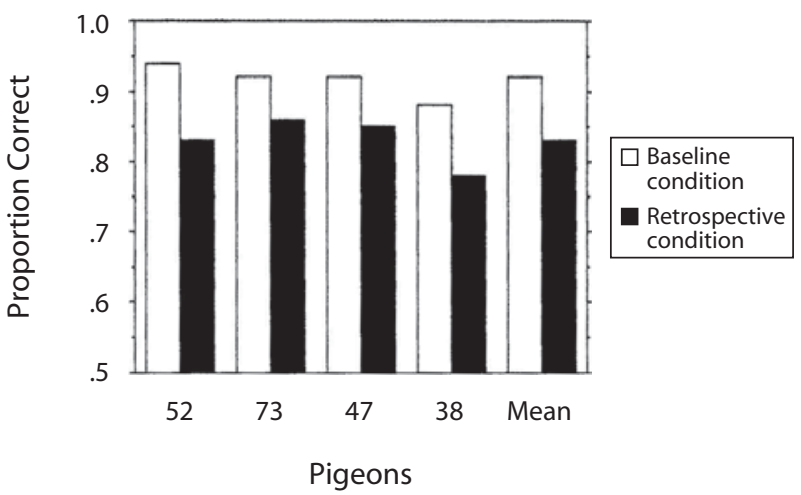

Figure 3. Accuracy (proportion correct) for the retrospective condition compared with accuracy under the baseline condition. The unfilled bars represent the baseline, and the filled bars represent retrospective testing. The top panel shows data from the short test range, and the bottom panel shows data from the long test range.

was significant $[F(1,3)=13.29]$. Tukey's HSD was used to make all pairwise comparisons of the four conditions. In the unique conditions, the measure for green key-light trials was significantly higher than for red key-light trials. In the common conditions, red and green trials did not differ. In the red and green conditions, performances under unique and common conditions were significantly different.

Figure 4 shows the results of conditions in which the identity of the test range was cued during both the sample and the choice phases (unfilled bars) and when the test range was cued during the sample but not during choice (filled bars). The top panel shows these comparisons for the short set and the bottom panel for the long set. Data are shown for each pigeon, with the means of those data on the far right of each panel.

The differences in cuing conditions displayed in Figure 4 are not as large as those displayed in Figure 3. If anything, the mean accuracy for the long test range was higher for the prospective condition than for the baseline condition, in which information about test range was available both during and after the sample. A two-way ANOVA was used to evaluate the reliability of the trends in Figure 4. The factors were cue type and test range. The main effect of cue type was not significant $[F(1,3)=3.13]$, nor were the main effects of test range or the interaction between cue type and test range (both $F$ s $<1$ ).

In the previous figures and statistical analyses, we compared timing under retrospective and prospective cuing conditions with baseline conditions in which information about the test range was available throughout the trial. Figure 5 provides a direct comparison of performance under retrospective and prospective cuing conditions for the short set (top panel) and the long set (bottom panel).

Both panels show that accuracy was higher under prospective cuing conditions (dark hatched bars) than under retrospective conditions (light stippled bars). This difference in cuing condition was consistent across all birds and test ranges except for Pigeon 52 in the long set. The difference between cue conditions appears larger for the short set than for the long set, but that difference was not significant. Whereas a two-way ANOVA with cue condi-

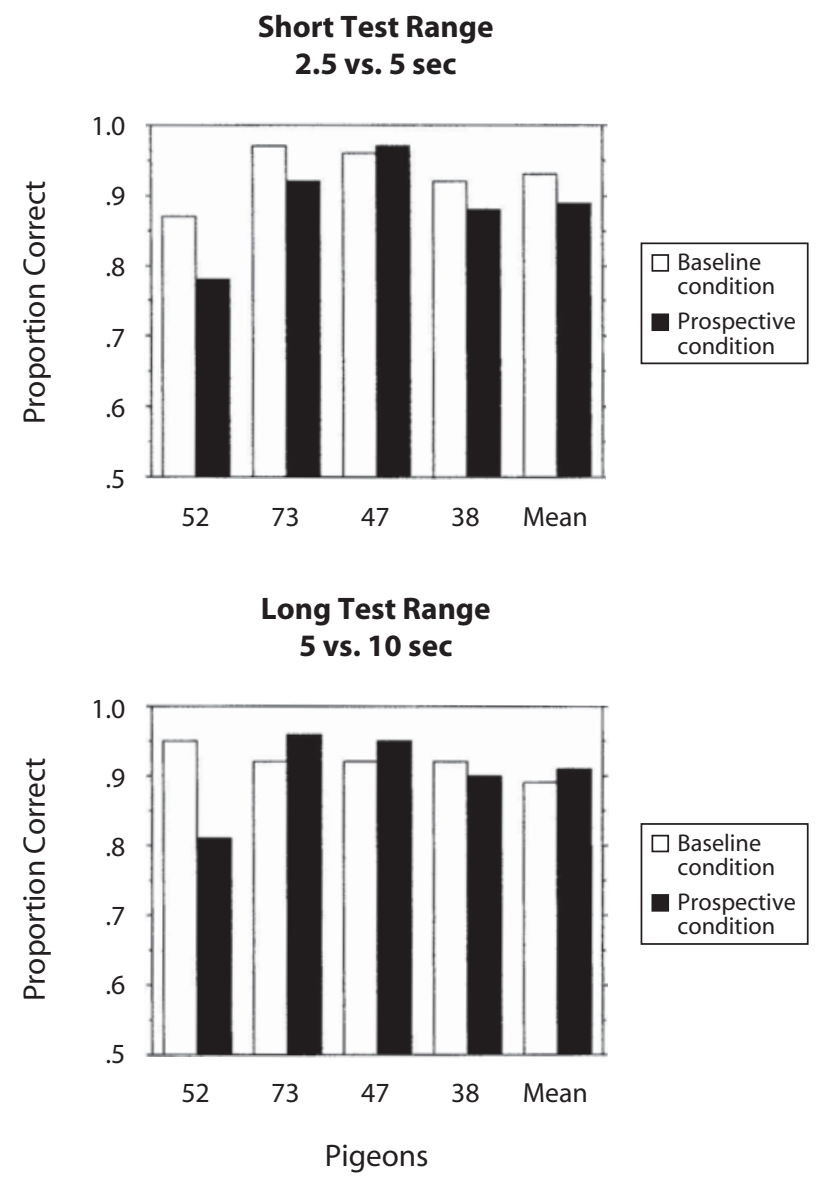

Figure 4. Accuracy (proportion correct) for the prospective condition compared with accuracy under the baseline condition. The unfilled bars represent the baseline and the filled bars represent prospective testing. The top panel shows data from the short test range and the bottom panel shows data from the long test range. 


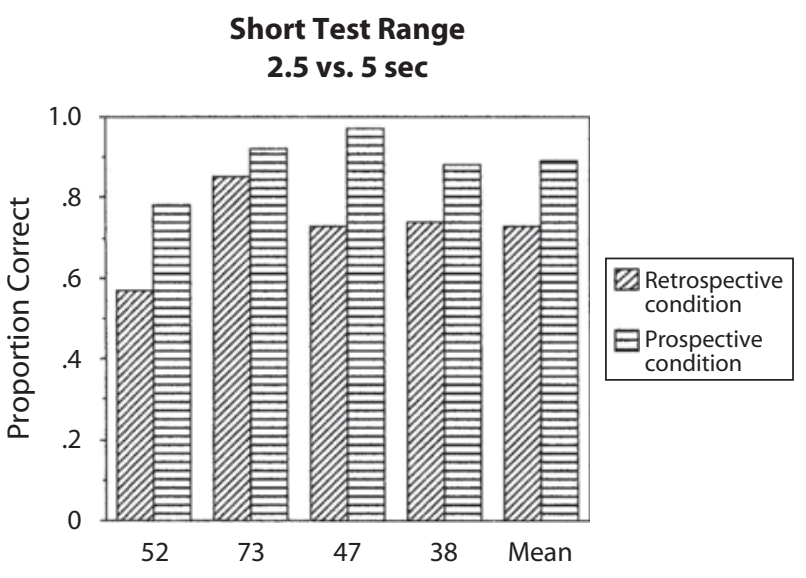

Long Test Range

5 vs. 10 sec

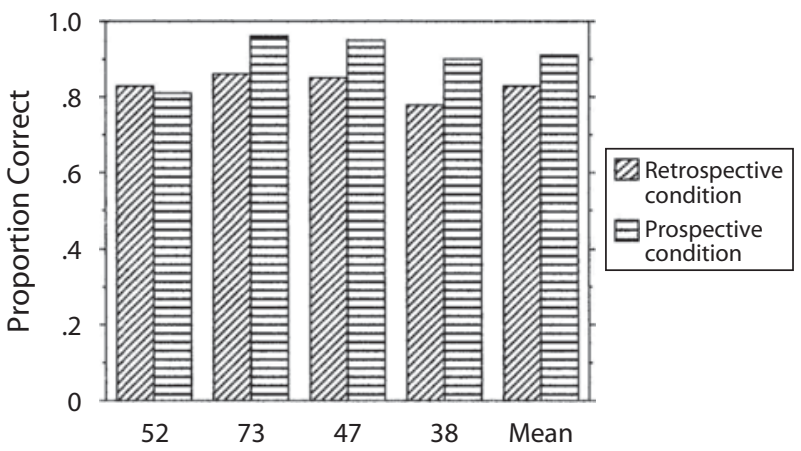

Pigeons

Figure 5. Accuracy (proportion correct) for the retrospective condition compared with accuracy under the prospective condition. The diagonal-hatched bars represent the retrospective condition and the horizontal-hatched bars represent the prospective condition. The top panel shows data from the short test range and the bottom panel shows data from the long test range.

tion and test range as the factors showed that the main effect of cue type was significant $[F(1,3)=19.49]$, the main effect of test range was not $[F(1,3)=7.80]$, nor was the interaction $(F<1)$.

Figure 6 shows the results of the probe tests with inconsistent cuing of range. For instance, a trial might start with a red light on the center key (short range) and end with green lights presented on the choice keys (long range), as is shown in Figure 2. The top panel of Figure 6 shows the results from the shortest and longest values from each test range $(2.5$ and $10 \mathrm{sec})$ when presented under the inconsistent situation. The dependent measure is the probability of the long response. Except for Pigeon 52 (who was indifferent to the color on the center key), the patterns are clear: When presented with a red sample of $2.5 \mathrm{sec}$ followed by green choice lights (cuing the long range), the pigeons tended to call the stimulus short (i.e., the probability of a long response was low; median $=16 \%$ ). When presented with a 10 -sec green sample followed by red choice lights (cuing the short range), the pigeons tended to call the stimulus long (i.e., the probability of a long response was high; median $=79 \%$ ). These results are not surprising, except perhaps that accuracy was lower than in the baseline condition for these stimuli even though, if $2.5 \mathrm{sec}$ was the short duration in the short range, it should have been an easy judgment to call it short for the long range, if coding were analogical. The scenario is identical for the 10 -sec sample. In other words, the consistency of the patterns of choices can be viewed as due to stimulus generalization based on the duration of the center-key sample.

The bottom panel of Figure 6 shows the more interesting results of probe tests for the 5-sec samples, which appeared in both the short and long training sets. In general, this sample was called short about $70 \%$ of the time. This choose-short bias was greatest when the sample was green (cuing the long set; unfilled bars in Figure 6; median = $80 \%$ short). The conflicting information at the time of decision (the red side keys) had minimal effect. Apparently, the pigeons' decisions were made before they were given
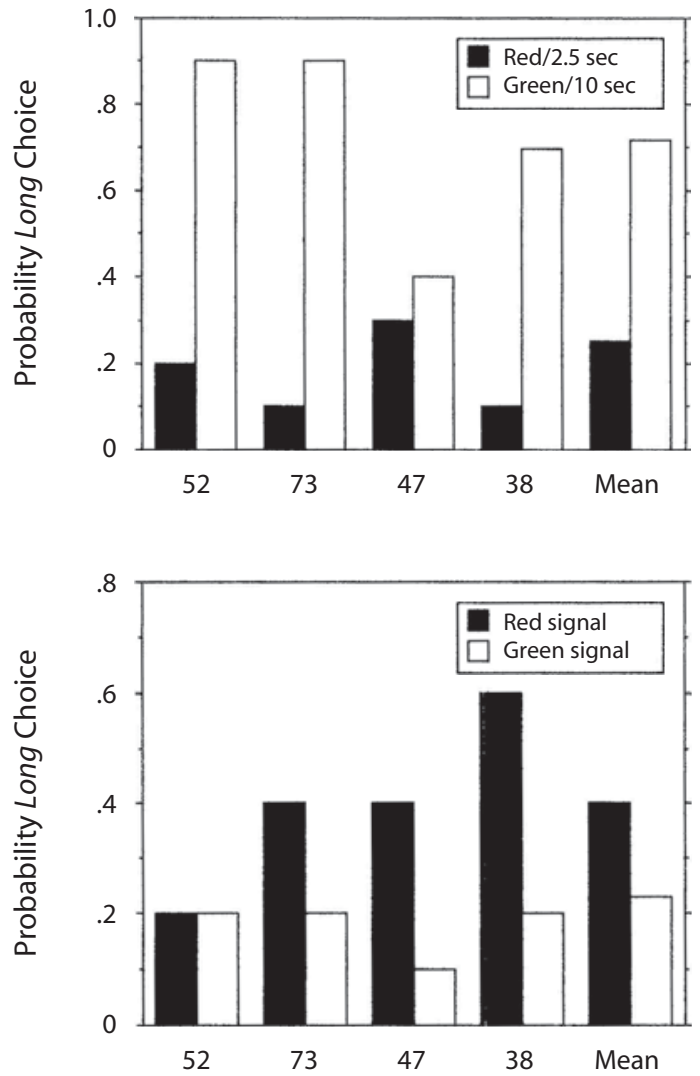

Pigeon

Figure 6. Data from conflict probe trials. The dependent measure is the probability of making a response to the long choice key. The top panel shows data from tests in which the signal key was the shortest value in the short test range (filled bars) and when it was the longest value in the long test range (unfilled bars). The bottom panel presents data from conflict tests where the test ranges shared a common duration $(5 \mathrm{sec})$. The filled bars indicate trials in which the signal light was red and followed by green choice-key lights; the unfilled bars represent trials in which the signal light was green and followed by red choice-key lights. 
the opportunity to choose. When the sample was red, cuing the short set, the decision moved toward long for all birds except Pigeon 52 (the median percent short falls to $60 \%$ ). The data in Figure 6 were analyzed with a two-way ANOVA with uniqueness (variable vs. common values) and center-key color (red vs. green) as the factors. The main effect of uniqueness was nonsignificant $(F<1)$, because the pattern of differences in the top and bottom panels was the opposite, canceling one another out. The main effect of key color was significant $[F(1,3)=12.1]$, and the interaction of these two factors was significant $[F(1,3)=$ 12.6]. Post hoc comparisons (Tukey's HSD) were used to make comparisons among all four cells of the design. The difference between red and green trials under the unique condition was significant. The difference between red and green trials under the common condition was not significant. The differences for both red and green under unique and common conditions were significant.

\section{DISCUSSION}

The results involving different methods of cuing the stimulus duration test range are clear. When the cue for the test range appeared at the end of the trial, signaled by the choice-key lights (retrospective timing), accuracy was significantly lower than that in the baseline condition, in which both the signal for the duration and the choice lights identified the test range. However, when the cue for the test range was presented at trial onset followed by ambiguous colors on the choice keys (prospective timing), accuracy did not differ from that of the condition in which both the signal and the choice-key colors informed the pigeons of the test range. Direct comparisons of retrospective and prospective training regimens demonstrated that the accuracy of discrimination was higher under prospective conditions. Thus, the ability to anticipate test range in advance was beneficial relative to a situation in which the test range was identified only at the end of the trial. The main question is what kind of behavioral mechanism can account for the difference between retrospective and prospective timing.

The data from conflict trials extend and confirm the results described above by demonstrating that the color of the temporal signal exerted more control over choice than the color of the choice keys. This result is clearly visible in the top panel of Figure 6; the center key signaled either the shortest value of the short range or the longest value of the long range. The signal was followed by choice-key colors that signaled the opposite range. The separation of the dark and white bars indicated that the birds attended to the sample stimulus. As is shown in the bottom panel of Figure 6, a shared value of the short and long ranges $(5 \mathrm{sec})$ was presented with either a red or green sample color followed by the opposite key color for the choice phase. Except for Pigeon 52, the separation of the dark and white bars indicates that sample key color exerted more control over choice.

A behavioral approach to temporal judgments (e.g., Killeen \& Fetterman, 1988; Machado, 1997) is consistent with these results. In the prospective condition, the center- key color cued the test range and presumably triggered a learned sequence of behavioral states that, at the time of choice, provided a cue to the correct response. Under the retrospective condition, however, the sample did not inform a pigeon of the test range and could not elicit a unique sequence of behaviors that provided a cue to the correct choice response. Although we did not observe the birds' behavior during the experiment, there is evidence from other studies demonstrating a correlation between behavior and choice in temporal discrimination tasks. Fetterman, Killeen, and Hall (1998) video recorded and categorized the behaviors of pigeons as they performed a temporal discrimination. They found strong correlations between behaviors that preceded choices and the choice that was made at the end of the trial. Similarly, Machado and Keen (1999) reported a relationship between behaviors that occurred before choice and the choice response that was emitted. In their experiment, observations of the birds' behaviors during the signal revealed that behavioral patterns preceding choice predicted the ensuing choice response. Although the patterns differed across birds, they were consistent for individual subjects and predicted differences in the steepness of psychometric functions.

The data in the bottom panel of Figure 6 from the critical conflict trials (common value for both test ranges) suggest that cuing the range during the sample exerted more control over choice than cuing the range during the choice. All birds except one (Pigeon 52) showed a stronger preference for choosing long when given a red center key than when given a green center key. This result can be construed as support for the notion that the pigeons probably initiated differential response chains well in advance of making a choice response. This hypothesis is consistent with data reported by Machado and Keen (1999) and Machado and Arantes (2006) and with a categorical account of timing (Kraemer et al., 1985).

As was clearly described by Arantes and Machado (2008), the classic model of time estimation, SET (see, e.g., Gibbon, 1977), is context independent: Accumulation of pulses should occur independent of the cuing condition. Differences in behavior should be under the control of the choice stimuli, which would signal the animal to select different comparison sets to compare with the working memory. Stated another way, SET is inherently retrospective, because the cognitive machinery cannot be brought to bear on the discrimination until the choice stimuli are available. But our results show the opposite pattern: Range information during the choice (and not during the sample) is much less useful than range information during the sample (whether or not range information is present during the choice). Oliveira and Machado (2009) indicated that information about time is differentially accumulated, more slowly in the long set, in a manner consistent with the slower execution of behavioral chains in contexts with lower densities of reinforcement (Beam, Killeen, Bizo, \& Fetterman, 1998; Morgan, Killeen, \& Fetterman, 1993). Thus, for pigeons as well as for humans (Block \& Zakay, 1997; Grondin \& Plourde, 2007; Urcuioli, Zentall, Jackson-Smith, \& Steirn, 1989; and possibly for the same reasons), in duration discrimination tasks, it is advanta- 
geous to know in advance what the choice context will be at the end of a trial.

\section{AUTHOR NOTE}

Correspondence concerning this article should be addressed to J. G. Fetterman, Indiana University-Purdue University Indianapolis, 402 N. Blackford St., Indianapolis, IN 46202 (e-mail: gfetter@iupui.edu).

\section{REFERENCES}

Arantes, J., \& Machado, A. (2008). Context effects in a temporal discrimination task: Further tests of the scalar expectancy theory and learning-to-time models. Journal of the Experimental Analysis of Behavior, 90, 33-51.

Beam, J. J., Killeen, P. R., Bizo, L. A., \& Fetterman, J. G. (1998). How reinforcement context affects temporal production and categorization. Animal Learning \& Behavior, 26, 388-396.

Block, R. A., \& ZaKaY, D. (1997). Prospective and retrospective duration judgments: A meta-analytic review. Psychonomic Bulletin \& Review, 4, 184-197.

Church, R. M. (1984). Properties of the internal clock. In J. Gibbon \& L. Allan (Eds.), Timing and time perception (pp. 566-582). New York: New York Academy of Sciences.

Church, R. M., \& Deluty, M. Z. (1977). The bisection of temporal intervals. Journal of Experimental Psychology: Animal Behavior Processes, 3, 216-228.

Fetterman, J. G. (1996). Dimensions of stimulus complexity. Journal of Experimental Psychology: Animal Behavior Processes, 22, 3-18.

Fetterman, J. G., Killeen, P. R., \& Hall, S. (1998). Watching the clock. Behavioural Processes, 44, 211-224.

GibBon, J. J. (1977). Scalar expectancy theory and Weber's law in animal timing. Psychological Review, 84, 279-325.

Gibson, J. J. (1975). Events are perceivable but time is not. In J. T. Fraser \& N. Lawrence (Eds.), The study of time (Vol. 2, pp. 142-149). New York: Springer.

Grondin, S. (2001). From physical time to the first and second moments of psychological time. Psychological Bulletin, 127, 22-44.

Grondin, S., \& Plourde, M. (2007). Judging multi-minute intervals retrospectively. Quarterly Journal of Experimental Psychology, 60, 1303-1312.

Guttman, N., \& Kalish, H. I. (1956). Discriminability and stimulus generalization. Journal of Experimental Psychology, 51, 79-88.

Honig, W. K., \& Thompson, R. K. R. (1982). Retrospective and prospective processing in animal working memory. In G. H. Bower (Ed.), The psychology of learning and motivation (Vol. 16, pp. 239-283). San Diego: Academic Press.

JENKINS, H. M., \& Harrison, R. H. (1960). Effects of discrimination training on auditory generalization. Journal of Experimental Psychology, 59, 246-253.
Killeen, P. R., \& Fetterman, J. G. (1988). A behavioral theory of timing. Psychological Review, 95, 274-295.

Kraemer, P. J., Mazmanian, D. S., \& Roberts, W. A. (1985). The choose-short effect in pigeon memory for stimulus duration: Subjective shortening vs. coding models. Animal Learning \& Behavior, 13, 349-354.

Machado, A. (1997). Learning the temporal dynamics of behavior. Psychological Review, 104, 241-265.

Machado, A., \& Arantes, J. (2006). Further tests of the Scalar Expectancy Theory (SET) and the Learning-to-Time (LeT) model in a temporal bisection task. Behavioural Processes, 72, 195-206.

Machado, A., \& KeEN, R. (1999). Learning to time (LeT) or scalar expectancy theory (SET)? A critical test of two models of timing. Psychological Science, 10, 285-290.

Marks, L. E. (1991). The dynamics of ratio scaling. In S. J. Bolanowski, Jr., \& G. A. Gescheider (Eds.), Ratio scaling of psychological magnitude: In honor of the memory of S. S. Stevens (pp. 27-42). Hillsdale, NJ: Erlbaum.

Morgan, L., Killeen, P. R., \& Fetterman, J. G. (1993). Changing rates of reinforcement perturbs the flow of time. Behavioural Processes, 30, 259-272.

Oliveira, L., \& Machado, A. (2009). Context effect in a temporal bisection task with the choice keys available during the sample. Behavioural Processes, 81, 286-292.

RoItBLat, H. L. (1980). Coding and coding processes in pigeon shortterm memory. Animal Learning \& Behavior, 8, 341-351.

StubBs, A. (1968). The discrimination of stimulus duration by pigeons. Journal of the Experimental Analysis of Behavior, 11, 223-238.

Terrace, H. S. (1966). Stimulus control. In W. K. Honig (Ed.), Operant behavior: Areas of research and application (pp. 275-344). New York: Appleton-Century-Crofts.

UrCUIOLI, P. J., \& Zentall, T. R. (1986). Retrospective coding in pigeons' delayed matching-to-sample. Journal of Experimental Psychology: Animal Behavior Processes, 12, 69-77.

Urcuioli, P. J., \& Zentall, T. R. (1992). Transfer across delayed discriminations: Evidence regarding the nature of prospective working memory. Journal of Experimental Psychology: Animal Behavior Processes, 18, 154-173.

Urcuioli, P. J., Zentall, T. R., Jackson-Smith, P., \& Steirn, J. N. (1989). Evidence for common coding in many-to-one matching: Retention, intertrial interference, and transfer. Journal of Experimental Psychology: Animal Behavior Processes, 15, 264-273.

Wearden, J. H. (2003). Applying the scalar timing model to human time psychology: Progress and challenges. In H. Helfrich (Ed.), Time and mind II: Information-processing perspectives (pp. 21-39). Cambridge, MA: Hogrefe \& Huber.

(Manuscript received October 16, 2009; revision accepted for publication October 26, 2009.) 